Article

\title{
The AgTech Startup Perspective to Farmers Ex Ante Acceptance Process of Autonomous Field Robots
}

\author{
Friedrich Rübcke von Veltheim * and Heinke Heise
}

Department of Agricultural Economics and Rural Development, Georg-August-University of Göttingen, Platz der Göttinger Sieben 5, 37073 Göttingen, Germany; heinke.heise@agr.uni-goettingen.de

* Correspondence: veltheim@uni-goettingen.de; Tel.: +49-551-39-24264

Received: 31 October 2020; Accepted: 14 December 2020; Published: 17 December 2020

\begin{abstract}
Autonomous vehicles not only provide a new impetus in the development of car models in the automotive industry - even in agriculture there has recently been talk of autonomous field robots (AFR). Great expectations are placed on these digital assistants from a wide variety of perspectives. However, it is still unclear whether they will make the transition from market niches to broad-based distribution. Apart from various factors, this depends on user acceptance of this new technology expected by the innovators, since this is likely to be essential for the further development of AFR. For this purpose, the ex ante user acceptance of farmers from the perspective of various AgTech startups with AFR involvement in Europe was investigated in this exploratory and qualitative study. The Technology Acceptance Model (TAM) served as the basis for the developed interview guideline. In summary, the results confirm that a variety of factors potentially influence farmer acceptance and AFR diffusion from the perspective of AgTech startups, with perceived usefulness being considered the main motivation for using AFR. The interviewed experts believe that AFR will initially be used in crops that have relatively high costs for crop protection treatments before becoming economically attractive for other crops. The basic prerequisite for a successful market launch is an adjustment of the legal framework, which sets standards in relation to AFR and thus, provides security in the production process. The results could support political decision-makers in dealing with this new technology and AFR manufacturers in the promotion of AFR.
\end{abstract}

Keywords: acceptance; AgTech startups; autonomous; robot; TAM

\section{Introduction}

The megatrend of digitalization has not stopped at the agricultural sector. Rapidly developing technologies and infrastructures are opening up new perspectives that could even lead to a rethinking of entire farming systems [1]. For example, tractors as the main work equipment for arable farmers are slowly but surely being joined in their development by highly accurate, sensor-based, and intelligently linked field robots that can perform certain tasks autonomously, much more precisely, and much more sustainably either alone or in swarms with other units. The development of such autonomous field robots (AFR), which are becoming increasingly economically attractive, is mainly being driven by the growing demand for qualified workers in agriculture and the public debate about the impact of farming practices on the environment (e.g., the use of pesticides, over-fertilization, and soil compaction) and thus, addresses all three pillars of sustainability (economic, environmental, and social) [2]. Social majorities can generate political pressure, which can lead to legal changes in pesticide and fertilizer application and force farmers to adapt their farming practices. AFR, some of which are still at the prototype stage, can perform specific tasks without an operator, apply pesticides on a plant-by-plant basis, or control weeds mechanically, which is why AFR could become more important in the future [3]. With its autonomous operation, these machines reduce the workload of farmers and protect them 
from unnecessary contact with harmful chemicals. Due to AFR's better scalability, smallholder farms, which have often been considered uneconomical, could become more economically attractive by adopting such robots, which could lead to a rethink in process in the agricultural sector, away from the motto: "bigger is better" [4].

However, the introduction of autonomous technologies in agriculture is also accompanied by some concerns. For instance, although the driving of farm machinery would be abolished, new tasks would be added, such as AFR's monitoring and programming, for which farmers may lack qualified staff [3]. In addition, Devitt [5] fears that farmers may not be able to trust unmanned robots working out of sight and that by handing over tasks to artificial intelligence (AI), they would lose agricultural knowhow in the long run and thus, suffer an even greater loss of social recognition. A similar conclusion was reached by Kester et al. [6], who, using the example of special crops, revealed a conflict between the farmers' support of efficiently operating AFR and a lack of confidence in such technologies.

Despite the concerns expressed above, there is broad agreement that AFR will claim its place in modern agriculture in the future, but it remains unclear when and to what extent this will happen. For instance, the King [4] argues that the initial reluctance of established agricultural machinery manufacturers to develop AFR is due to the fact that their existing business models are being compromised. In addition, the risk of damaging reputation by a possible malfunction of the first AFR is much higher for established agricultural machinery manufacturers than for largely unknown AgTech (AgTech (Agricultural Technology) is used in this article as a generic term for all technical innovations affecting the data-driven, networked, digital agriculture of the future) startups. However, AFR also offer a whole range of new business models for agricultural machinery manufacturers, such as on-demand supply of AFR to farmers in return for a rental fee or as a cloud-based pay-per-use model [7].

Another opportunity can be seen in the ongoing development of agricultural engineering through a disaggregated approach in the form of several small robot units where large machines hit the legal size and weight limits [8]. Since digital technologies such as AFR collect and analyze large amounts of data in order to fully unfold their potential, not only AgTech startups but also large IT companies such as IBM and Google are competing with established agricultural machinery manufacturers. As these new players will claim their share of the market, it is all the more important for the current market leaders to assess whether there is indeed a future market for AFR and, if so, to what extent [9]. Therefore, when estimating the factors influencing the ex ante acceptance of AFR by farmers, the perspective of various AgTech startups as new market entrants appears to be highly interesting.

However, there have only been a few studies on the technology acceptance process in relation to AFR in agriculture so far. Redhead et al. [3] attribute this to the fact that this is a new, potentially disruptive technology and that not much is known about how AFR could be integrated into current farming practices. Therefore, they conducted contextual interviews with nine farmers from large-scale farms in Queensland (Australia). The farmers interviewed were particularly interested in the reduction of weed control costs and the time saved by the absence of an operator when using AFR. However, they also feared the reliability of the small robot units in an uncontrolled environment, the time required for monitoring, the complexity of AFR as well as the lack of required infrastructure in terms of high-speed mobile data networks. Overall, however, they were enthusiastic about a possible adoption of AFR, which was particularly true for farmers who were already using precision agriculture (PA) technologies on their farms. This can be confirmed by the findings of Salimi et al. [10], according to which farmers are more likely to adopt automated technologies the more they understand their usefulness. Therefore, the authors [10] surveyed 378 people with agricultural backgrounds in Iran in 2020 about factors influencing the adoption of agricultural automation. In 2018, Rial-Lovera [11] surveyed 14 agricultural stakeholders in California (USA) on their AFR acceptance behavior and revealed labor shortages and rising labor costs, as well as a lack of awareness of the potential benefits of AFR and the lack of compatibility between agricultural equipment as the main reasons for an ex ante acceptance of AFR by farmers. Using a wider definition of the term, Caffaro and Cavallo [12] conducted 
a survey on Smart Farming Technologies (STF) at a northern Italian agricultural fair and found that the sociodemographic characteristics of farmers influence their adoption behavior of STF. Overall, it can be concluded that there is a research deficit in the investigation of the technology acceptance process and diffusion of AFR in agriculture, as most studies focus only on the effect of certain facets and tend to ignore the multidimensionality of the acceptance process, leading to imperfect understanding of the underlying complexity of acceptance factors and diffusion barriers [13,14].

One group whose perspective appears particularly interesting in this context is, in addition to farmers (as buyers), the AgTech startups themselves (as suppliers). Following Roger's [15] theory of the diffusion of innovations, the identification and successful targeting of the right group of farmers should be a top priority for suppliers in order to invest their resources into attracting the right people. In addition, the supplier's knowledge of existing drivers and barriers to the diffusion of AFR as an essentially affected party is usually higher than among other stakeholders. AFR are currently in an early market introduction phase, in which it will be decided whether the "critical mass" [15] of adoptions will be reached and the technology will be successfully established to a broader market or not.

The aim of this paper is therefore to examine first the barriers to the diffusion of AFR by providing insights into the ex ante acceptance process of AFR. To this end, the present study examines various acceptance factors influencing the technology's diffusion from the perspective of AFR-developing AgTech startups. Since it is especially the user acceptance expected and already experienced by the suppliers that is essential for the further development and implementation of AFR, AgTech startups have collected data from farmers themselves. By interviewing the startups, it is possible to obtain aggregated knowledge about the acceptance of many farmers. Therefore, the data have been gathered through qualitative expert interviews at the International Forum of Agricultural Robotics (FIRA) in Toulouse (France) in December 2019.

\section{Materials and Methods}

Due the relatively small number of AgTech startups with AFR involvement in Europe and a lack of empirical research on the acceptance of AFR, a qualitative approach for data collection and analysis was chosen: expert interviews using a semi-standardized guideline to specify the wording and order of the questions, thus ensuring a uniform procedure [16]. Besides the fact that a quantitative survey was not suitable given the relatively small statistical population, expert interviews offer several advantages, since answering open questions requires higher cognitive effort from the respondents than answering closed questions and can therefore reveal more in-depth information [17]. In order to collect the data, we conducted interviews with experts from ten different AgTech startups specialized in AFR at the International Forum for Agricultural Robotics (FIRA) in Toulouse (France) in December 2019. The open and neutral formulated questions were split into six thematic blocks: drivers and barriers, economics, environmental impacts, legal constraints, socioeconomic impacts, and technology. Following a brief introduction to the topic, the experts were interviewed in person, leaving them free to add questions or topics not covered in the interview guide. The results were extracted using a qualitative content analysis according to $[16,18]$, which is described in more detail in Section 2.2. For this purpose, individual statements from the interviews are assigned to previously developed, theory-based categories (described as factors in Section 2.1.) after summarizing and aggregating the information.

\subsection{Study Design}

This 14 question-long guide (see Appendix A) was based on the factors influencing the ex ante user acceptance of new technologies based on the Technology Acceptance Model (TAM) [19]. These factors cover perceived usefulness, perceived ease of use, and external factors. Since the subject of this study is the future use of AFR, it can be assumed that farmers have had little or no experience in dealing with this new technology, which is why the factors of attitude toward using and actual system use have 
been excluded from this analysis. In addition, Chuttur [20] was able to demonstrate a direct influence of perceived usefulness and perceived ease of use on the behavioral intention. According to [19], the perceived usefulness is the subjective probability with which a potential user will adopt a certain technology (in this case AFR) to improve his work performance in an organizational context. In contrast, the perceived ease of use describes the level of simplicity of a technology expected by a potential user. Both perceived usefulness and ease of use can be influenced by various external factors [10,21-23]. In order to address the diversity of perceived usefulness, this study explicitly addresses the underlying facets of an economic benefit in terms of, for example, higher harvest expectations, (labor-) cost savings or an increase in economic efficiency, and the facets of an environmental benefit. The effect of perceived ease of use on perceived usefulness is assumed to be positive, since a higher degree of simplicity of a technology is beneficial to its usefulness $[10,11,23,24]$. The following external factors have been added based on the available literature on the topic: compatibility, farm manager characteristics, information, legal framework, social influence, and workforce availability $[3,5,6,10-12,14,23,25,26]$. The external factor compatibility takes findings from diffusion theory into account, which has shown that the technical design strongly influences user acceptance [25]. Compatibility means the possibility of combining AFR with existing technology and thus, successfully integrating it into working practice. Therefore, we expect an effect on the perceived usefulness and the perceived ease of use. As another external factor, we have introduced the farm manager's characteristics in order to meet socioeconomic aspects such as age, educational level, and risk aversion [14]. Following an approach from PA research, the external factor information represents the data collected by AFR and its strategic operational use as well as associated data protection and data autonomy, for which we assume a direct influence on the perceived usefulness. The sociopolitical discussion on chemical plant protection products in Europe is leading to increasing legal restrictions on the use of pesticides in agriculture (e.g., Germany: [27]). In addition, the use of autonomous technologies on public roads is still not regulated in a way that is appropriate to the present time, which is why we assume that the legal framework has an influence on perceived usefulness [28]. We therefore defined the external factor legal framework as the degree to which a farmer believes that organizational and legal infrastructures exist to support the use of AFR. Social influence was taken into account as a further external factor to counteract the limitation of the TAM to ignore the social environment. The fact that the social environment has an influence on the acceptance of technology has been proven several times with the follow-up models TAM2 and the unified theory of acceptance and use of technology (UTAUT). Furthermore, farmers are influenced in their strategic decisions by their social environment [29], which is why we assume a direct relationship between social influence and perceived usefulness. The availability of workforce has been repeatedly cited in the screened literature as a driver for the development and adoption of AFR, which is why a direct influence on the behavioral intention to use AFR is assumed from this fifth and last external factor in this study $[2,30]$. The assumptions based on the factors mentioned above are shown in the following figure (Figure 1). 


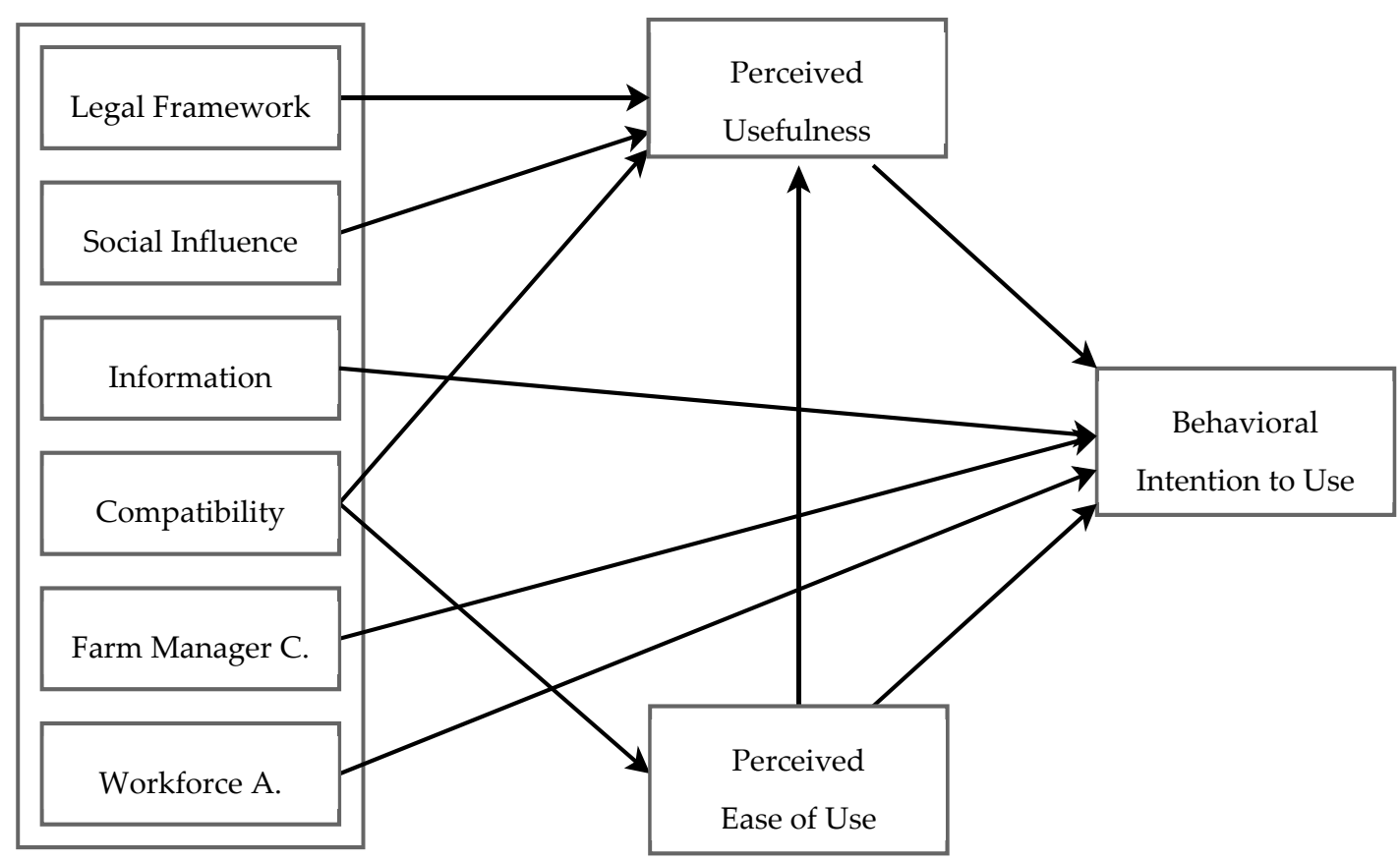

Figure 1. Modified TAM in the context of autonomous field robots.

\subsection{Data Analysis}

A qualitative content analysis by extraction according to $[17,18]$ was used to analyze the data. This was performed in three steps: transcription and data exploration, identification of statements related to the acceptance factors, and summarization and interpretation of the extracted information.

The first step was to transcribe the recorded interviews in full length. The resulting transcripts were made anonymous using the method of factual anonymization. In this process, the extracted data are anonymized to such an extent that links to the individual experts can only be decrypted with a disproportionately high effort [31]. As a next step, the information relevant to the research objective of this study was extracted from the transcripts and assigned to the TAM factors described above (external factors, perceived usefulness, and perceived ease of use) that served as categories as defined by [17]. The differentiation of the factors from each other was based on their definitions, anchor examples, and coding rules (see Table A1 in the Appendix A). Since there are hardly any studies available for the research object in an agricultural context, the TAM factors were kept open in order to allow the integration of new factors which did not occur in the reviewed literature. Thus, all relevant information of the raw material could be examined under consideration of the interrelations between the factors influencing the acceptance of AFR. The methodical procedure was supported by the software "f4-analysis".

\subsection{Sample Description}

The ten selected AgTech startups surveyed for this study are listed in the table below (Table 1). Among these are some of the most promising competitors in this emerging industry, such as the current market leader Naïo Technologies, but also two EU-funded projects aiming to develop a market-ready product. The total number of potential AFR AgTech startups in Europe is probably in the lower two-digit range but is currently difficult to overview. Thus, the experts interviewed are very likely to cover a representative part of the total population of AgTech startups with AFR involvement in Europe. 
Table 1. Sample description.

\begin{tabular}{|c|c|c|c|}
\hline Company & Incorporation & Headquarter & AFR Involvement \\
\hline Agrointelli & 2015 & Aarhus, Midtjylland (Denmark) & multiple task robot \\
\hline AgrOnov & 2015 & $\begin{array}{l}\text { Bretenière, } \\
\text { Bourgogne-Franche-Comté (France) }\end{array}$ & AFR consulting \\
\hline Deepfield Robotics & 2008 & $\begin{array}{c}\text { Ludwigsburg, } \\
\text { Baden-Württemberg (Germany) }\end{array}$ & multiple task robot \\
\hline Ecorobotix & 2011 & $\begin{array}{c}\text { Yverdon-les-Bains, } \\
\text { Waadt (Switzerland) }\end{array}$ & $\begin{array}{l}\text { solar-powered chemical } \\
\text { weed control robot }\end{array}$ \\
\hline K.U.L.T. & 2012 & $\begin{array}{l}\text { Vaihingen an der Enz, } \\
\text { Baden-Württemberg (Germany) }\end{array}$ & $\begin{array}{c}\text { autonomous mechanical } \\
\text { weed control }\end{array}$ \\
\hline Naïo Technologies & 2011 & Escalquens, L'Occitanie (France) & weed control robots \\
\hline $\begin{array}{c}\text { Robotics for } \\
\text { Microfarms (ROMI) }\end{array}$ & 2017 & Barcelona, Catalonia (Spain) & multiple task robot \\
\hline SITIA & 1986 & $\begin{array}{c}\text { Bouguenais, Pays de la Loire } \\
\text { (France) }\end{array}$ & multiple task hybrid robot \\
\hline VineScout & 2016 & Valencia, Valencia (Spain) & $\begin{array}{l}\text { monitoring robot } \\
\text { (vineyard) }\end{array}$ \\
\hline VitiBot & 2016 & Reims, Grand Est (France) & $\begin{array}{l}\text { multiple task robot } \\
\text { (vineyard) }\end{array}$ \\
\hline
\end{tabular}

Agrointelli was founded in 2015 in Denmark, aiming to offer a fully automated farming system for arable farming. As a first step, they developed "Robotti", a versatile and autonomous multiple task robot. AgrOnov, founded in 2015 as a non-profit organization, offers a network to accompany the development of AgTech startups and to promote information and knowledge about their products. The Robert Bosch startup Deepfield Robotics emerged from a research project in 2008 with the publicly funded project "BoniRob", an autonomous robot that can, among other things, measure soil quality and remove weeds. Deepfield Robotics has recently changed its name to "farming revolution" and shifted its focus to mechanical weed control by autonomous robot platforms [32]. Ecorobotix has been developing solar-powered AFR since 2011, which control weeds with high precision using very small amounts of chemicals. The chemical company BASF is one of its investors [33]. K.U.L.T. provides innovative weeding technology for robots and has its roots back in the 1980s. After being temporarily dissolved, they have been newly founded in 2012 under the name "K.U.L.T. Kress Umweltschonende Landtechnik $\mathrm{GmbH}^{\prime \prime}$ and are known for their patented finger weeder. Naïo Technologies is one of the AFR pioneers, founded in 2011. They offer a variety of different AFR for weed control. To date, they have already sold nearly 150 AFR [34]. Robotics for Microfarms (ROMI) is an EU-funded project with a duration of 5 years (2017-2022) and a budget of about EUR 4 million. Their aim is to develop open and lightweight robotic platforms for microfarms, helping the farmers to reduce weeds and to monitor their crops [35]. SITIA is an industrial small- and medium-sized enterprise (SME). In 2019, SITIA launched a hybrid autonomous tractor called "TREKTOR". VineScout has also emerged from an EU-funded project (with a budget of around EUR 2 million), in which a monitoring system (decision support system) embedded in a small and cost-efficient vineyard robot is to be developed to market maturity between 2016 and 2020 [36]. Vitibot was founded in 2016. They developed the AFR "Bakus", a fully electric and autonomous straddle tractor designed to work in the vineyards.

All respondents are directly or indirectly involved in the development process of AFR and were represented as exhibitors at the International Forum of Agricultural Robotics (FIRA) in Toulouse from 8 to 10 December 2019, where the personal interviews took place.

\section{Results}

\subsection{Perceived Usefulness}

All experts agree that AFR must be economically attractive, otherwise one can only: “( ... ) touch a little, little, little part of the farmers— the technophile." (The extracted statements are expressed by 
direct quotations, where (...) indicates that text has been skipped, while [] indicates that text has been added. This was done for practical reasons.) (E2). For the majority of the respondents (E2, E3, E4, E5, E6, E8, E10), economic attractiveness is even the most important acceptance factor, because: “(...) a farmer is also an entrepreneur, (...) profitability is the ultimate exclusion criterion." (E4). Consequently, the adoption of AFR by farmers is seen as particularly important in areas where the costs of e.g., weed control (E3), workforce (E4, E5, E7), or time (E9) are relatively high. For expert 8, the price of the robot plays a less important role, since: “(...) the return of investment is probably more important than the cost of the machine and the cost of having the machine or renting the machine just to make sure that in a short period of time you will get back the money." (E8). Expert 9 points out that AFR are expensive to purchase but cheaper to maintain than tractors.

Most of the experts interviewed (E1, E2, E3, E6, E7, E9) also ascribe relevance to the ecological benefits of AFR for the acceptance process among farmers, as another sub-item of perceived usefulness, to the extent that they are forced to deal with resource-saving technologies due to increasing legal restrictions in plant protection. However, one expert sees in this sociopolitically driven trend towards a more sustainable agriculture also an opportunity for the development of new technologies: " $(\ldots$ ) the current socio-political discussion about reducing pesticides. At the moment, this is a door opener for technologies (... ). That's already a big lever at the moment." (E3). With regard to the weighting of this influence, opinions differ. Experts 2, 4, 8 and 9 agree that the ecological benefits are a good sales argument, but not the major aspect. Three other experts differentiate that this aspect is more important for organic farmers than for conventional farmers (E3, E4, E7). For two experts (E5, E10), the ecological advantages are even the most important influencing factor, whereas expert 7 believes that AFR remains a tool and that it always depends on how it is used: "I mean all those robots, it's still tools. So, depends on how you use it. If the idea is trying to reduce the chemicals, robots can be a good tool, (... ) if you want to use it in a different way [e.g.,] doing the spraying with more aggressive chemicals, because you don't have the people inside. (... ) So, I think it is not the question of the tool, it's what to do with this." (E7). The argument of battery-powered AFR concepts is also seen as controversial. For experts 2 and 5, electric engines have an acceptability enhancing effect, as they are more environmentally friendly and quieter than previous diesel engines. Expert 7 points out that the disposal of batteries is a problem that is often ignored, and for which one has to find a sweet spot. For expert 4, the ecological benefit is: “(...) marketing. Marketing and a big lie, because robots have batteries depending on how they drive. An electric car is not more ecological than when I drive my 20-year-old diesel." (E4).

According to most experts (E2, E3, E4, E5, E6, E8, E10), it is very important for AFR to operate reliably in order to be accepted. For about half of them (E5, E6, E8, E10), safety and reliability are even the second most important acceptance factors after economic efficiency. Experts 2, 3, 6, 7, and 8 see many teething problems with this new technology that need to be eliminated in order to increase its acceptance. Therefore, expert 7 believes that it is important that: " (... ) they [farmers] just want to see it working [in the field] and for what I understand they have enough need of this kind of tools to be able to accept" (E7). Two of the respondents (E2, E6) add that farmers want to see that they remain in control and are not completely replaced by AFR. Expert 7 counters that there are still enough tasks that humans can do better than robots and that AFR cannot replace the farmer but only support him.

With regard to perceived usefulness, the relationships assumed at the beginning of the study (Figure 1) are reflected in many ways in the experts' statements. For example, it was emphasized several times that both the ecological and economic benefits of AFR have a direct influence on the behavioral intention to use. In addition, two new relations have been identified. First, the farm structure, as a new external factor, has a direct influence on perceived usefulness as it has a higher value for organic farms. Second, the ecological benefits of AFR appear to be increasing in value as a result of changes in the legal framework in terms of an ongoing ban on pesticides. Thus, the legal framework also has a direct influence on perceived usefulness (see Figure 2). 


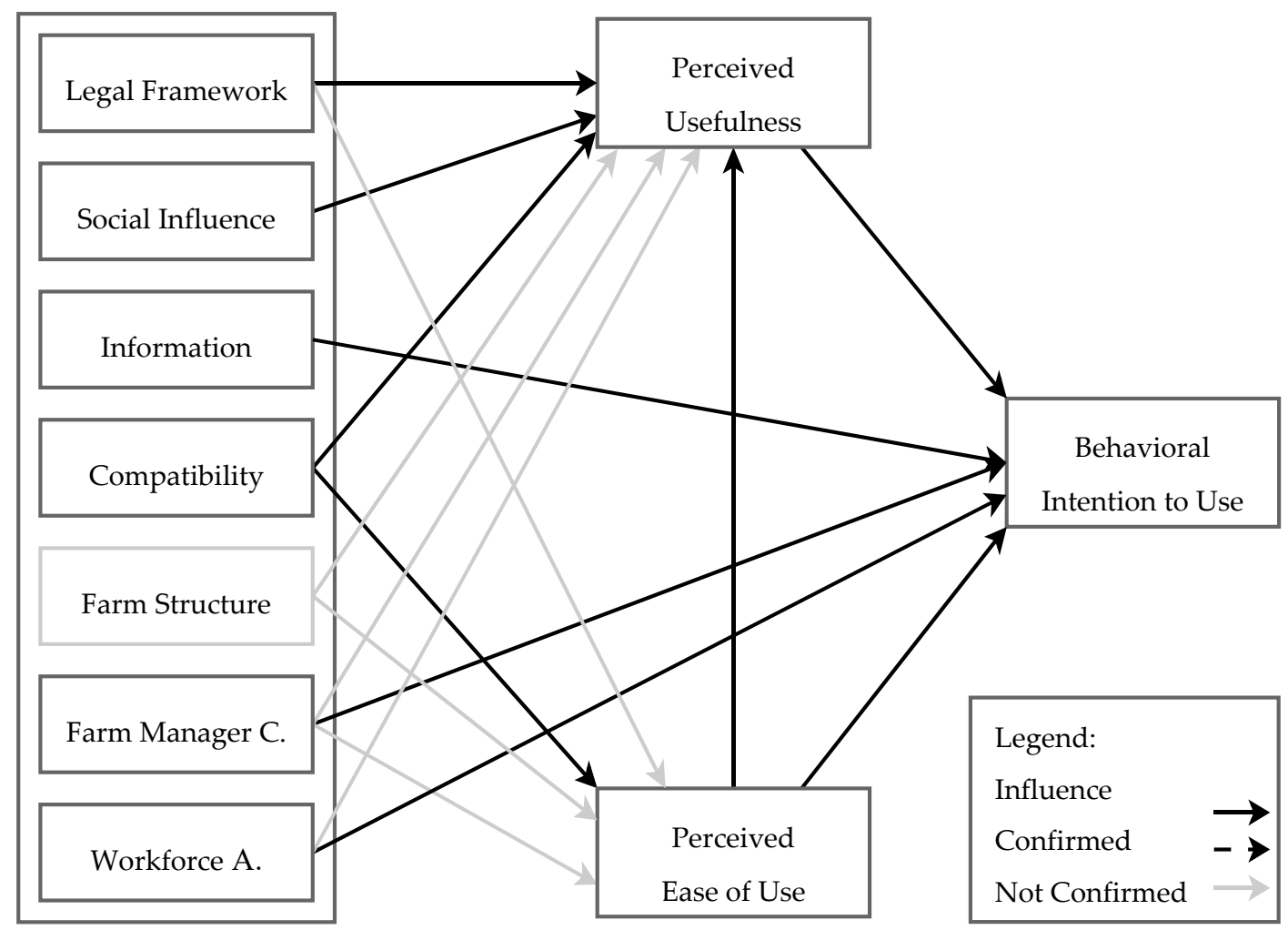

Figure 2. Examined TAM in the context of autonomous field robots.

\subsection{Perceived Ease of Use}

The perceived ease of use was confirmed by most experts as an important acceptance factor (E2, E3, E4, E7, E8, E9), and, for expert 8, it is actually the most important factor for farmers: "But I think for farmers [the most important factor] is the complexity of the machines. ( ... ) it's too difficult to use them." (E8). For this reason, four of the respondents argue that AFR should be designed as simple and clean as possible (E3, E7, E8, E9). Expert 5, on the other hand, sees things completely differently: "If you can use a smartphone, you can use a robot." (E5). Experts 2 and 8 add that it is important to provide farmers with a training program, with expert 7 focusing mainly on practical demonstrations to help farmers overcome any fear of dealing with AFR. Even after the purchase of AFR, according to two experts, good support must be guaranteed so that farmers do not have to worry and to: "( . . ) be afraid of not having the right support at the right time." (E8). Therefore, it would be: "( . . ) easier for the farmer accept, to take risk." (E2).

For the TAM factor of perceived ease of use, the assumed influence on the intention of use was reflected in the answers of the respondents, too. The easier AFR are to operate, the more farmers are willing to use them, according to the experts. Hence, the indirect influence of perceived ease of use on perceived usefulness could be confirmed by the proposed training programs; the more farmers are trained about the possible applications of AFR, the more likely they are to recognize a possible benefit or added value of this technology (see Figure 2).

\subsection{Legal Framework}

All experts interviewed agreed on the fact that the legal framework strongly influences the acceptance and speed of adoption of AFR in the agricultural sector. In this context, experts 6, 7, and 10 call for general legislation on the handling of robots before regulating AFR in particular, especially with regard to safety issues: "I think it definitely will cause a problem and we need new legislations for robots in general and especially for agriculture. Especially if it's a person working alongside the robot." (E6) and: 
"Which is also related to how we can technically ensure that we will not have an accident and this question is quite difficult to solve outdoors." (E7). So far, the legal framework is relative: "(...) loosely defined what is allowed and what is illegal." (E1), which is why mandatory standards would be helpful, otherwise every manufacturer would try to find a way around it: "So, all the actors of robotics agriculture work together to find some compromise to put some robots on the field." (E5). Due to the perceived lack of governmental support, experts 2, 4, and 8 assume that the diffusion rate of AFR in Europe will slow down, which will give other countries a head start: "[it] is crossing different development rates in different countries. So, we see for example that Japan is releasing faster robots on the same level of development. Whereas Europe and the US are more restrictive, and they are more concerned about safety law. So probably we will see in Japan and Australia first prototypes hitting the market." (E8). In addition to the legal requirements for AFR, three of the interviewees (E3, E7, E8) see a more restrictive legislation for the use of pesticides in agriculture, which could have a positive effect on the acceptance of AFR: "On the other hand, however, the regulations, especially in the area of plant protection, are currently so drastically discussed that people say: 'I need to take the step now, I have to do this or crops will die'." (E3).

The assumed effect of the legal framework on perceived usefulness was unanimously confirmed by the interviewed experts and at the same time, represents the basic requirement for a successful diffusion of this new technology. Not only the legal requirements for the use of AFR but also the tightening legal situation regarding the use of pesticides in agriculture seem to have an impact on acceptance by farmers. In addition, a new relationship of the legal framework to ease of use could be identified, since the sooner legal standards for AFR are introduced, the fewer compromises or legal grey areas have to be used by manufacturers and the easier AFR can be operated (see Figure 2).

\subsection{Social Influence}

Most respondents agree that social influence in the form of sociopolitical pressure has an impact on farmers' decisions (E2, E3, E4, E7, E8, E9), although expert 9 notes that: "It used to be almost nothing, but it is changing really fast. I think the pressure from the government with regulation, but it mostly comes from the end-user. They want something more sustainable and I think this is pushing really hard on the farmers. So that is definitely something they are considering more and more and it's growing really, really fast." (E9). The discussion about the use of pesticides in agriculture in particular sometimes seems to be driven more by emotion than by fact: "We have conducted many, many interviews and we have had people [farmers] there who were almost close to tears. They say they've had enough." (E3) or: "But it's not always taking into account with very precise technical date, it's more passionate, you know." and: "(...) they [consumers] have this crusade against glyphosate." (E8). According to one respondent (E7), this discussion has an influence on the acceptance of AFR among farmers, even before technical aspects, although in his opinion, the subject of labor safety should not be disregarded. Experts 2, 3, 4, 7, and 8 also see this sociopolitical discussion as a good opportunity for AFR to enter the market in order to meet the demands of society: "If this solution [AFR] can give the farmer some positive recognition it will be more easy [to accept] for the farmer." (E2).

The assumed relationship of social influence on perceived usefulness was clearly confirmed. AFR are seen by farmers as useful tools to counteract social pressure and the associated increasing regulation of pesticide use (see Figure 2).

\subsection{Information}

The vast majority of the respondents (E1, E2, E4, E5, E6, E7, E8, E10) agree that data protection and data autonomy play a role in AFR's acceptance process, of which most consider this role to be very important (E2, E4, E5, E7, E10). Thus, according to experts 2, 4, and 6, it is important for farmers that: "(...) the data continue to belong to them [farmers] and that they have full control over the data." (E4), because: "(...) they want to be independent." (E2). Several interviewees (E3, E5, E7, E8) see this rather in a twofold way: "On the one hand, [some] say: 'yes, look, this is my field, my production, so to speak, and I would like to keep the pictures with me'. (...) On the other hand (...) they say: 'of course I'm very happy to share this 
information because I know that the system will then improve continuously, and I will benefit from sharing this information'." (E3), which is also influenced by the type of farm, because in viticulture, for example, exists: "(...) a culture of keeping secrets." (E8) can be important for the success of the company (E7, E8). For one of the interviewees (E4), most farmers do not really understand the term data protection, which is why it is important for AFR's acceptance process to sell the issue to farmers in the right way. Expert 9, on the other hand, sees no influence of the information factor, because: "(...) everyone is working with Google for example or e-mail for store your pictures, so everything is on Google, so it doesn't seem to matter for most of the people. Big companies yes, but small farmers no. Big companies will look at that, but I don't think there is anything to fear." (E9).

It appears that the assumed influence of the factor information on behavioral intention was not just confirmed but also strengthened by the majority of the respondents. Only one expert (E9) saw it in a different light. However, the strength of this effect depends to a large extent on the farm manager characteristics and the farm structure, as the issue of data protection and data autonomy can be more important in viticulture, for example, than in arable farming, where the experts perceive a certain dichotomy among farmers (see Figure 2).

\subsection{Compatibility}

All the respondents agreed that AFR's compatibility with existing technology is very important for the perceived usefulness and ease of use among farmers. Because: "(...) autonomous machines are the natural evolution of farm machinery." (E8) and: "(...) it would be nice if you could combine the past and the future." (E3). Otherwise, it can be confusing for farmers sometimes (E3). According to Expert 6, AFR have to fit into the given farm structures and not vice versa: "I think they [farmers] want to have a robot they can adapt to their own farm. They don't want to do it the other way around. They don't want to adapt their farm to the robot." (E6), whereby this again depends on the farm size: "like small farms that don't have necessarily like machinery and stuff you can adapt with their own habits. Not necessarily with the tractors. So, I think it depends on the farms, but if there is already a tractor it is easier for them to buy a robot, if the robot is adapted to the tractor, I think." (E6). At the same time, three experts (E6, E8, E10) underlined that the existing AFR concepts are not yet compatible enough. Two of the respondents (E3, E8) also made it clear that in this process: "(...) nevertheless the core know-how of these companies [established agricultural machinery manufacturers] must be taken along. It is unrealistic to expect that robotics manufacturers will suddenly revolutionize the seed planting process." (E3).

In terms of the TAM factors, the assumed relationships of AFR's compatibility with perceived usefulness and perceived ease of use were confirmed. The better the new technology can be combined with the established technology, the less confusing it is for farmers and the easier it is to use. At the same time, the perceived usefulness of AFR is higher if it can be integrated easily into existing farm structures (see Figure 2).

\subsection{Farm Manager Characteristics}

There were differing views among the respondents on the role of the farmers' age in the acceptance process. Four experts (E1, E4, E6, E9) consider that: “(...) age for example is not something that prevents people from buying a robot." (E1). Expert 9 adds that: "The elderly doesn't like technology most of the time, just like a smartphone they don't like it most of the time. But farmers are used to like technology in general, so I think the age doesn't matter." (E9). Three of the interviewees (E2, E3, E7) share this view insofar as younger people do not necessarily show a higher level of acceptance than older people but are more sensitive or have a greater affinity for technology and that they: “(...) consider that it's more like present. So, like this technology is for today and people a bit older or lower educated tend to think that it's maybe more the future." (E7). On the other hand, experts 4 and 8 attribute an effect on acceptance of age by all means: "Of course, younger farmers tend to be quicker in using such technology. I say, if you plot a curve, acceptance tends to increase with age." (E4). One interviewee also sees an opportunity in AFR: "(...) to have a new 
better image of agriculture and farming in general for a new and younger generation. I hope it would be that." (E6), in order to counteract the increasing ageing in the sector.

With regard to the educational level of the farmers, the respondents were in agreement. For instance, about half of them (E2, E3, E4, E7, E9) were convinced that there is a correlation between level of education and AFR acceptance. Experts 3 and 8, however, tend to see AFR manufacturers as having a responsibility to design AFR with such simplicity that the level of education should not play a role. Two of the interviewees (E6, E8) find that there is no such influence at all. Instead, acceptance depends more on the farm structure, since: "(...) tractors and combines, these machines are already sophisticated, so they [farmers] know how to use them." (E8).

According to the experts, although the risk appetite or curiosity about innovative technologies plays a role in the intention to use AFR, this varies with the personality of the farmer (E3, E4, E6) and is sometimes correlated with the level of education (E1). One of the respondents therefore suggests that leasing concepts should be offered first, so that: “(...) I do not have the entry barriers for the farmer. And then it's relatively easy, then the farmer actually has relatively little risk for the first year and that's the way it has to be." (E3).

\subsection{Workforce Availability}

There is general agreement among the respondents that the workforce availability factor has an influence on the acceptance process. For example, all the experts surveyed see the increasing shortage of labor in agriculture as a driver for AFR's adoption. For two of the interviewees (E1, E7), the lack of skilled workers is even one of the most important drivers of acceptance: "So, they have big issues finding people to drive the tractors and do the job. So, the main problem is this." (E7). In addition, there is an increasing pressure from the trend to use less pesticides, which means more mechanical weed control measures, resulting in more labor-intensive weed control (E7). Three experts (E2, E5, E8) point out that for some physically demanding jobs in agriculture, you need to be in good shape or it is simply unhealthy, which is why you hardly find anyone to do it; therefore, there is no risk of a displacement effect: "(...) nobody wants to do it, because it's very boring and very difficult (...) because we don't have someone. So, for me the robot won't have any impact on the labor market." (E5). Experts 3, 6, 7, and 10, on the other hand, see an effect on the labor market in Eastern Europe, since the use of AFR means that fewer seasonal workers are needed, which could lead to a social problem: "But if you imagine that like $80 \%$ of the labor is replaced by robots it's also a social question in terms of which society we want to build and how we will deal with that." (E7) and: "I think we're playing with new tools and not necessarily thinking about the impacts it's going to have. But we have to think about it of course." (E6). Two of the respondents (E8, E9) counter that: "(...) a new set of new jobs [is] coming with digital technologies, like data analyzer, like maintenance teams, so there will be jobs." (E8). Finally, one expert points out that: "(..) a person I hire to work in the field for an hour will always be more expensive than a robot." (E4).

The assumed direct influence of workforce availability in the adapted TAM on the behavioral intention to use was clearly confirmed by the need to address labor shortages. In addition, a new relationship was found between workforce availability and perceived usefulness, because the less workers are available, the greater the perceived usefulness of AFR for farmers. This relationship is also confirmed by the fact that the removal of the driver reduces the cost of performing the task (see Figure 2).

\section{Discussion and Conclusions}

AFR are considered to be a promising technology to address, at least in part, the many problems in agriculture identified in this study. Nevertheless, there are hardly any studies to date that deal with the multidimensionality of AFR's ex ante user acceptance process. Such understanding is particularly important, in some cases existentially, for AgTech startups that have committed themselves to this new technology. Therefore, the aim of this explorative paper was to gain a first qualitative understanding of the factors influencing the ex ante user acceptance and diffusion of AFR from the perspective of AgTech 
startups to compare the results with the statements of farmers (as buyers) in a follow-up study. For this purpose, guideline-based interviews with ten European AgTech startups dealing with agricultural robotics were conducted at the FIRA in Toulouse (France). The interview guideline was based on the TAM according to [19] and was supplemented by external factors (legal framework, social influence, information, compatibility, farm manager characteristics, and workforce (availability)) taken from the scientific literature on this topic.

In conclusion, it was found that due to the scope of the topic, many factors influence the acceptance of farmers from the AgTech startups' point of view. In general, the assumed relationships in the TAM were not only confirmed, but also supplemented by a new factor (farm structure) and several new relationships, which once again demonstrates the transferability of the TAM to various problems of agricultural acceptance research (see also [37]).

Perceived usefulness was identified by the respondents as the most important or one of the most important factors influencing the ex ante user acceptance of AFR, with economic benefits ranking ahead of ecological ones. This finding is supported by the results of $[10,38]$, who also investigated the ex ante user acceptance factors of automation and PA technologies based on a TAM. In this context, the price of AFR plays a role in so far as the return of investment must pay off in the end and not necessarily its absolute amount, which partly confirms the results of [11]. The author described high investment costs as a possible barrier to acceptance of AFR in a similarly qualitative survey. Therefore, the experts interviewed in this study see AFR first in crops with particularly high labor costs, such as special crops but also row crops, such as sugar beet, before they become economically attractive on a broader scale, which is also confirmed in other studies $[2,8,39]$. According to the experts, the ecological advantages of AFR, with the exception of organic farms, have a rather indirect effect on acceptance, as farmers are more or less forced to deal with such technologies due to the progressive reduction of legally permitted pesticide use, which is in line with [40]. At the same time, this sociopolitical pressure is an opportunity for AFR to enter the market more broadly. A similar conclusion was reached by the authors in [41] as a result of their systematic literature review. They particularly emphasized the importance of the ecological benefits of PA and the trend towards more sustainable agriculture. Reliability and safety issues of AFR were also considered by most respondents as an important part of perceived usefulness, which is in line with several other studies [3,5,42]. Overall, a better communication of the economic but also environmental benefits can contribute to an increase in ex ante user acceptance, which, regarding the reliability of AFR, should include practical demonstrations.

The respondents also attributed an important role in the diffusion process to ease of use. This confirms the studies of [24,25] on agriculture and on TAM in general [19]. In addition, Salimi et al. [10] have found that there is a significant positive correlation between automation features such as compatibility, low complexity, reduced workforce needs, etc., and perceived ease of use. According to the experts, AFR should be designed as simply as possible, which is in line with the findings of [3], according to which too much complexity of AFR can represent an important barrier to its diffusion.

The experts consider the legal framework to be a highly important factor and a major barrier to the diffusion of AFR in the EU. For example, the general operation of AFR is currently considered by both the experts and [40] to be legally uncertain and thus, declared a grey area. Dörr et al. [40] also point out that the regulations regarding the use of AFR vary widely around the globe, with Australia, Japan, and the USA being further along than Europe, where scientists tend to register a standstill. In the case of Germany, the federal government has at least stated its intention to establish the legal prerequisites for autonomous vehicles by the end of its term of office, to clarify liability issues [43]. A proposed solution to liability issues or to clarify the cause of an accident in connection with AFR could be the use of a "black box" analogous to aviation [44]. In addition, the experts emphasized a large, acceptance-influencing effect through the tightening of existing laws affecting agricultural practice; more precisely, by the ever more restrictive regulations on the use of pesticides in agriculture, which are forcing farmers to change. This effect is also confirmed by [40], who add that the future 
market share of autonomous machines will depend largely on regional legislation, while [2] add that legal framework may well have an influence on the economic benefits of AFR.

The main opinion of the interviewees that social influence in terms of social pressure for more sustainable farming practices also affects perceived usefulness and thus, indirectly the behavioral intention to use AFR has been confirmed several times in the scientific literature [45-47]. Zander et al. [48] conclude that farmers increasingly feel social criticism as a burden and are thus, influenced in their strategic decisions [29]. Devitt [5] argues that farmers may lose agricultural know-how in the medium as well as long term using AFR and fear a resulting loss of social reputation. This is confirmed by [10], who observed a significant negative correlation between social factors and perceived usefulness of automation adoption in Azerbaijan's agricultural sector. In contrast, a consumer survey in the EU showed that only six percent of the respondents would agree to a ban on robots in agriculture [49].

With respect to the influence of collected information by AFR, there is a large consensus among the experts that this is particularly important for the acceptance process among farmers, as on the one hand, their independence is important to them and on the other hand, they want to keep control of the machinery and certain business secrets (e.g., in viticulture). In their media analysis, Schleicher and Grandorfer [50] identified data protection and data autonomy as important barriers to acceptance of PA technologies in agriculture. In contrast, the experts surveyed in a study by [11] explicitly did not see data protection and data autonomy as barriers to the diffusion of AFR in agriculture. These contradictory results can possibly be explained by the dependence of the factor information on the characteristics of the farmer and the structure of the farm, as expressed by the experts interviewed in this survey.

The compatibility of AFR was also confirmed in its direct relevance to perceived usefulness and perceived ease of use and its indirect relevance to the behavioral intention to use. This is a particularly important transition phase from existing technologies to digital technologies in order to reach farmers accordingly and not to shy away from the feared complexity of the new system $[11,51]$. This is also confirmed by the results of [25], who conducted a quantitative survey among farmers on PA technology acceptance.

The farm structure, as a newly revealed influencing factor, seems to have a direct effect on perceived usefulness, as for example, AFR's ecological added value is higher for organic farms than for conventional farms. On the other hand, new technologies, such as AFR, can be better integrated into existing farm processes if the structural requirements (e.g., the degree of digitization) are met. Thus, Dörr et al. [40] see the farm structure factor as a possible reason for regional differences in AFR adoption. In addition, Shockley et al. [39] see an opportunity for smallholder farms in particular to gain economic benefits over large farms by using more scalable AFR, which is in contrast to the results for technology adoption in general, where larger farms tend to adopt new technology rather than small farms $[52,53]$.

The farm manager's characteristics were seen as relevant to the acceptance process, despite some disagreement among experts. Thus, the findings of [5] that better trained and younger farmers are more willing to adopt AFR could only be partially confirmed. While the experts agreed with the influence of educational level, as confirmed by [12] for PA technologies or by [19] in general, they disagreed on the influence of age, as AFR should be designed in such a simple way that age is not relevant at all. Again, possible demonstrations of AFR could be helpful in overcoming possible barriers to acceptance due to the personal characteristics of the plant manager.

The availability of the workforce was also confirmed as an important factor influencing AFR's acceptance, the main argument being the existing shortage of skilled workers. This confirms the findings of [11], according to which the availability of workforce and rising wages will increase AFR's diffusion in the agricultural sector. The experts interviewed emphasized that there would be no major displacement of existing jobs, as there was already an existing shortage. The situation is different for seasonal workers from low-wage countries. In such countries, reference [30] therefore sees the introduction of AFR coming later than in countries with higher wage levels. Lowenberg-DeBoer et al. [2] 
believe that migration flows and the resulting sociopolitical discussion also have an influence in this case. One expert agrees that replacing a driver with an AFR will always be cheaper than driver-operated machines. In addition, the experts see a contrary movement in the sociopolitical demand for a further reduction of pesticides, as this means more mechanical weed control, which in turn is more labor-intensive. However, respondents also noted that AFR will create new jobs, which is in line with [1], who argue that AFR could attract more highly qualified workers and thus, make agriculture more attractive to young people again.

Since these are empirically collected data, caution and certain limitations must be exercised in interpreting the results with regard to the examined ex ante user acceptance of AFR. First, the respondents are exclusively AgTech startups with AFR involvement, which may have an overly optimistic view of this new technology and their view on the acceptance of the farmers automatically shows not actual acceptance but their view on it. On the other hand, some of them also gained experience with diffusion barriers and the group of "early adopters" (e.g., Naïo Technologies as the market leader has already sold more than 120 AFR). Thus, a different sample composition could lead to different results [54]. Second, this is the ex ante user acceptance of a technology with which most farmers probably have had no contact so far and therefore, little can be said about the actual motivation for a possible adoption. Furthermore, the categorization of the expert statements to the different factors will always remain partly subjective. Causal relationships, as they can be calculated in e.g., quantitative studies using partial least squares (PLS) analysis, cannot be identified in this qualitative paper. Therefore, no hypotheses have been tested, as they cannot be statistically validated in terms of their significance.

However, the results offer various starting points for further research into the acceptance of autonomous machines in agriculture. Subsequently, the qualitative results must be quantified by surveying the farmers directly to verify or reject the results in a comparison, which is planned in a follow-up study. Furthermore, it would be interesting to investigate the conditions under which farmers would be willing to buy AFR (e.g., by using a choice experiment). Additionally, other stakeholder groups could be included in the analysis, for example, how consumers react to AFR depending on different designs. Furthermore, the results could support political decision-makers in dealing with this new technology (especially with regard to the creation of a contemporary legal framework for AFR) and AFR manufacturers in the promotion of their products among farmers. In conclusion, the findings of this and related studies can provide input for a successful implementation of AFR in agriculture in order to achieve the connected benefits for farmers, but most importantly for society in terms of a more sustainable and efficient farm management and thus, address the various social problems, as listed in the introduction.

Author Contributions: Conceptualization, F.R.v.V. and H.H.; methodology, F.R.v.V.; software, F.R.v.V.; validation, F.R.v.V. and H.H.; formal analysis, F.R.v.V.; investigation, F.R.v.V.; resources, F.R.v.V.; data curation, F.R.v.V.; writing — original draft preparation, F.R.v.V.; writing—review and editing, H.H.; visualization, F.R.v.V.; supervision, H.H.; project administration, H.H. All authors have read and agreed to the published version of the manuscript.

Funding: This research received no external funding.

Conflicts of Interest: The authors declare no conflict of interest.

\section{Appendix A}

Interview Guideline:

- Do you agree that the interview may be recorded and used in anonymous form for my research?

- What role will autonomous field robots play in agriculture over the next ten years?

- In your opinion, which factors inhibit/promote the acceptance of autonomous field robots among farmers?

- What influence do you attribute to the farm manager's age, educational level and risk propensity? 
- Do you consider the aspect of data protection and data sovereignty to be important for the acceptance of autonomous field robots among farmers?

- In which areas of agriculture can you imagine the use of autonomous field robots?

- How important do you think it is that autonomous field robots are compatible with different tools and possibly conventional equipment?

- Do you expect the introduction of autonomous field robots to have an impact on the distribution structure in the agricultural machinery market?

- What effects do you see on the agricultural labor market if autonomous field robots are used as standard?

- How do you assess the ecological added value as an influencing factor on the acceptance among farmers?

- Can conflicts with current legislation be a problem for the introduction of autonomous field robots in agriculture?

- In summary, which factors do you think have the greatest influence on the adoption of autonomous robots in agriculture?

- When do you think the commercial use of autonomous field robots in agriculture will start?

- How much will the robots cost?

Table A1. Coding Guide.

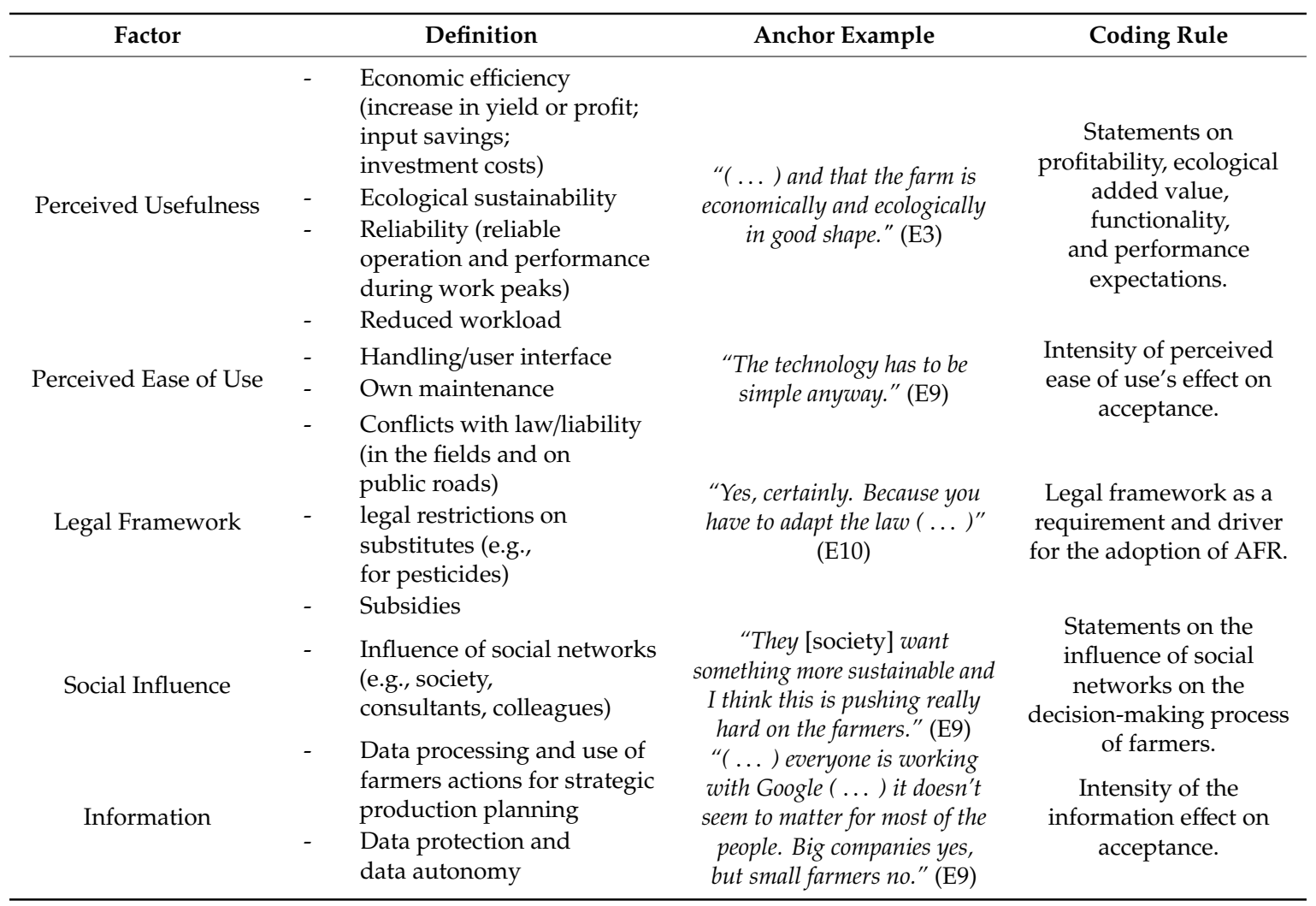


Table A1. Cont.

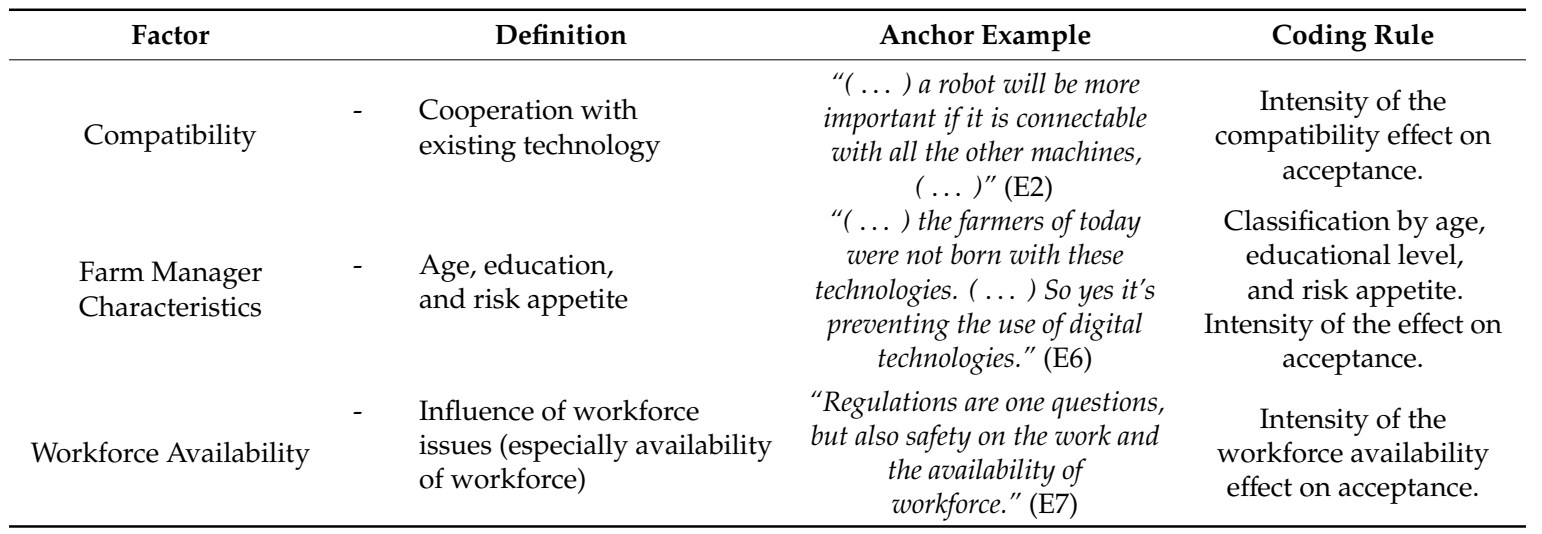

\section{References}

1. Duckett, T.; Pearson, S.; Blackmore, S.; Grieve, B. Agricultural robotics: The future of robotic agriculture. arXiv 2018, arXiv:1806.06762.

2. Lowenberg-DeBoer, J.; Huang, I.Y.; Grigoriadis, V.; Blackmore, S. Economics of robots and automation in field crop production. Prec. Agric. 2019, 21, 278-299. [CrossRef]

3. Redhead, F.; Snow, S.; Vyas, D.; Bawden, O.; Russell, R.; Perez, T.; Brereton, M. Bringing the farmer perspective to agricultural robots. In Proceedings of the CHI Conference on Human Factors in Computing Systems, Seoul, Korea, 18-23 April 2015; Association for Computing Machinery: New York, NY, USA, 2015. [CrossRef]

4. King, A. Technology: The future of agriculture. Nature 2017, 544, 21-23. [CrossRef] [PubMed]

5. Devitt, S.K. Cognitive factors that affect the adoption of autonomous agriculture. Farm Policy J. 2018, 15, 49-60. [CrossRef]

6. Kester, C.; Griepentrog, H.W.; Hörner, R.; Tuncer, Z. A survey of future farm automation-A descriptive analysis of survey responses. In Precision Agriculture '13; Stafford, J.V., Ed.; Wageningen Academic Publishers: Wageningen, The Netherlands, 2013; pp. 785-792. [CrossRef]

7. Erl, T.; Puttini, R.; Mahmood, Z. Cloud Computing: Concepts, Technology $\mathcal{E}$ Architecture, 1st ed.; Prentice Hall: Upper Saddle River, NJ, USA, 2013.

8. Minßen, T.-F.; Urso, L.-M.; Gaus, C.-C.; Frerichs, L. New plant production systems with autonomous agricultural machinery. ATZoffhighway 2015, 8, 6-11. [CrossRef]

9. Burwood-Taylor, L.; Leclerc, R.; Tilney, M. AgTech Investing Report: Year in Review 2015. AgFunder. Available online: https://research.agfunder.com/2015/AgFunder-AgTech-Investing-Report-2015. pdf (accessed on 31 October 2020).

10. Salimi, M.; Pourdarbani, R.; Nouri, B.A. Factors affecting the adoption of agricultural automation using Davis's acceptance model (case study: Ardabil). Acta Technol. Agric. 2020, 23, 30-39. [CrossRef]

11. Rial-Lovera, K. Agricultural robots: Drivers, barriers, and opportunities for adoption. In Proceedings of the 14th International Conference on Precision Agriculture, Montreal, QC, Canada, 24-27 June 2018; The International Society of Precision Agriculture: Monticello, IL, USA, 2018.

12. Caffaro, F.; Cavallo, E. The effects of individual variables, farming system characteristics and perceived barriers on actual use of smart farming technologies: Evidence from the Piedmont region, northwestern Italy. Agriculture 2019, 9, 111. [CrossRef]

13. Bukchin, S.; Kerret, D. Food for hope: The role of personal resources in farmers' adoption of green technology. Sustainability 2018, 10, 1615. [CrossRef]

14. Pathak, H.S.; Brown, P.; Best, T. A systematic literature review of the factors affecting the precision agriculture adoption process. Prec. Agric. 2019, 13, 1-25. [CrossRef]

15. Rogers, E.M. Diffusion of Innovations, 5th ed.; Free Press: New York, NY, USA, 2003.

16. Mayring, P. Qualitative Inhaltsanalyse: Grundlagen und Techniken, 12th ed.; Beltz: Weinheim, Baden-Württemberg, Germany, 2015.

17. Die schriftliche Befragung. Available online: https://www.hb.fh-muenster.de/opus4/frontdoor/deliver/index/ docId/489/file/SchriftlicheBefragung.pdf (accessed on 28 November 2020). 
18. Gläser, J.; Laudel, G. Experteninterviews und Qualitative Inhaltsanalyse als Instrumente, 4th ed.; VS Verlag für Sozialwissenschaften: Hesse, Germany, 2010.

19. Davis, F.D. Perceived usefulness, perceived ease of use, and user acceptance of information technology. MIS Q. 1989, 13, 319-340. [CrossRef]

20. Chuttur, M. Overview of the technology acceptance model. Origins, developments and future directions. Sprouts Work. Papers Inf. Syst. 2009, 9, 1-21.

21. Miller, L.H. A Study in man-machine interaction. In Proceedings of the National Computer Conference, Dallas, TX, USA, 13-16 June 1977; Association for Computer Machinery: New York, NY, USA, 1977. [CrossRef]

22. Benbasat, I.; Dexter, A.S. An investigation of the effectiveness of color and graphical information presentation under varying time constraints. MIS Q. 1986, 10, 59-83. [CrossRef]

23. Verma, P.; Sinha, N. Integrating perceived economic wellbeing to technology acceptance model: The case of mobile based agricultural extension service. Technol. Forecast. Soc. Change 2018, 126, 207-216. [CrossRef]

24. Adrian, A.M.; Norwood, S.H.; Mask, P.L. Producers' perceptions and attitudes toward precision agriculture technologies. Comput. Electron. Agric. 2005, 48, 256-271. [CrossRef]

25. Aubert, B.A.; Schroeder, A.; Grimaudo, J. IT as enabler of sustainable farming: An empirical analysis of farmers' adoption decision of precision agriculture technology. Dec. Support Syst. 2012, 54, 510-520. [CrossRef]

26. Paustian, M.; Theuvsen, L. Adoption of precision agriculture technologies by German crop farmers. Prec. Agric. 2016, 18, 701-716. [CrossRef]

27. 2035 Arable Farming Strategy_Prospects for Productive and Diverse Crop Farming. Available online: https://www.bmel.de/SharedDocs/Downloads/EN/Publications/ackerbaustrategie-en.pdf?_blob= publicationFile\&v=6 (accessed on 6 June 2020).

28. Alt, N. Gesetzliche Vorgaben für den Feldeinsatz von hochautomatisierten Landmaschinen. In Jahrbuch Agrartechnik 2018, 1st ed.; Frerichs, L., Ed.; Institute for Mobile Machines and Commercial Vehicles: Brunswick, Germany, 2018; pp. 1-7.

29. Kuczera, C. Der Einfluss des Sozialen Umfeldes auf Betriebliche Entscheidungen von Landwirten, 1st ed.; Margraf Publishers: Weikersheim, Germany, 2006; pp. 56-171.

30. Griepentrog, H.W. Automatisierung in der Außenwirtschaft. In Automatisierung und Roboter in der Landwirtschaft, 1st ed.; Molnar, C., Pikart-Müller, M., Eds.; Kuratorium für Technik und Bauwesen in der Landwirtschaft: Darmstadt, Germany, 2010; pp. 25-33.

31. Metschke, R.; Wellbrock, R. Datenschutz in Wissenschaft und Forschung, 3rd ed.; Druckerei Conrad GmbH: Berlin, Germany, 2002.

32. Weeding Service for Organic Farms. Available online: https://www.farming-revolution.com/ (accessed on 30 October 2020).

33. Ecorobotix Successfully Raises CHF 10.6 Million in Series B Financing with Lead Investors Capagro and BASF Venture Capital (in Englisch). Available online: https://www.basf.com/global/de/who-we-are/organization/ locations/europe/german-companies/BASF_Venture-Capital/publications/2018/P-18-530.html (accessed on 30 October 2020).

34. La Robotique Au Service de l'Agriculture. Available online: https://www.naio-technologies.com/ (accessed on 1 July 2020).

35. RObotics for MIcrofarms. Available online: https://cordis.europa.eu/project/id/773875/de (accessed on 1 July 2020).

36. Intelligent Decision from Vineyard Robots. Available online: https://cordis.europa.eu/project/id/737669/de (accessed on 1 July 2020).

37. Alambaigi, A.; Ahangari, I. Technology acceptance model (TAM) as a predictor model for explaining agricultural experts behavior in acceptance of ICT. Int. J. Agric. Manag. Develop. 2015, 6, 235-247. [CrossRef]

38. Pierpaoli, E.; Carli, G.; Pignatti, E.; Canavari, M. Drivers of precision agriculture technologies adoption: A literature review. Proc. Technol. 2013, 8, 61-69. [CrossRef]

39. Shockley, J.M.; Dillon, C.R.; Shearer, S.A. An economic feasibility assessment of autonomous field machinery in grain crop production. Prec. Agric. 2019, 20, 1068-1085. [CrossRef] 
40. Dörr, J.; Fairclough, B.; Henningsen, J.; Jahić, J.; Kersting, S.; Menning, P.; Peper, C.; Scholten-Buschhoff, F. Scouting the Autonomous Agricultural Machinery Market; Fraunhofer IESE: Kaiserslautern, Germany; Kleffmann Group: Lüdinghausen, Germany, 2019. Available online: https://www.iese.fraunhofer.de/content/dam/iese/en/dokumente/smart-farming/Scouting-theAutonomous-Agricultural-Machinery-Market.pdf (accessed on 31 October 2020).

41. Finger, R.; Swinton, S.; El Benni, N.; Walter, E. Precision farming at the nexus of agricultural production and the environment. Ann. Rev. Res. Econ. 2019, 11, 313-335. [CrossRef]

42. Bechar, A.; Vigneault, C. Agricultural robots for field operations: Concepts and components. Biosyst. Eng. 2016, 149, 94-111. [CrossRef]

43. Koalitionsvertrag zwischen CDU, CSU und SPD. 19. Legislaturperiode. Available online: https://www.bundesregierung.de/resource/blob/656734/847984/5b8bc23590d4cb2892b31c987ad672b7/ 2018-03-14-koalitionsvertrag-data.pdf?download=1 (accessed on 1 July 2020).

44. Recht für funktionale Sicherheit in der Autonomik. Available online: https://www.digitale-technologien. de/DT/Redaktion/DE/Downloads/Publikation/autonomik-Leitfaden2.pdf?_blob=publicationFile\&v=3 (accessed on 29 October 2020).

45. Foster, A.D.; Rosenzweig, M.R. Learning by doing and learning from others: Human capital and technical change in agriculture. J. Politic. Econ. 1995, 103, 1176-1209. [CrossRef]

46. Venkatesh, V.; Davis, F.D. A Theoretical extension of the technology acceptance model: Four longitudinal field studies. Manage. Sci. 2000, 45, 186-204. [CrossRef]

47. Venkatesh, V.; Morris, M.G.; Davis, G.B.; Davis, F.D. User acceptance of information technology: Toward a unified view. MIS Q. 2003, 27, 425-478. [CrossRef]

48. Zander, K.; Isermeyer, F.; Brügelt, D.; Christoph-Schulz, I.; Salamon, P.; Weible, D. Erwartungen der Gesellschaft an die Landwirtschaft; Stiftung Westfälische Landschaft; Johann Heinrich von Thünen-Institut: Brunswick, Germany, 2013.

49. Public Attitudes Towards Robots. Special Eurobarometer 382. Available online: https: //ec.europa.eu/commfrontoffice/publicopinion/index.cfm/Survey/getSurveyDetail/instrumen687ts/ SPECIAL/surveyKy/1044/p/3 (accessed on 1 July 2020).

50. Schleicher, S.; Grandorfer, M. Digitalisierung in der Landwirtschaft: Eine Analyse der Akzeptanzhemmnisse. In Digitale Marktplätze und Plattformen, Lecture Notes in Informatics 278; Ruckelshausen, A., Meyer-Aurich, K., Borchardt, C., Hofacker, J.-P., Loys, R., Schwerdtfeger, H.-H., Sundermeier, H., Theuvsen, F.B., Eds.; Gesellschaft für Informatik: Bonn, Germany, 2018; pp. 203-206.

51. Trendov, N.M.; Varas, S.; Zenf, M. Digital Technologies in Agriculture and Rural Areas: Status Report; Food and Agricultural Organization of the United Nations: Rome, Italy, 2019; pp. 118-120.

52. Anderson, P.D.; Wilson, N.P.; Thompson, D.G. Adoption and diffusion of level fields and basins. J. Agric. Res. Econ. 1999, 24, 186-203.

53. Bjornlund, H.; Nicol, L.; Klein, K.K. The adoption of improved irrigation technology and management practices-A study of two irrigation districts in Alberta, Canada. Agric. Water Manag. 2009, 96, 121-131. [CrossRef]

54. Melenhorst, A.-S.; Bouwhuis, D.G. When do older adults consider the internet? An exploratory study of benefit perception. Gerontechnology 2004, 3, 89-101. [CrossRef]

Publisher's Note: MDPI stays neutral with regard to jurisdictional claims in published maps and institutional affiliations.

(C) 2020 by the authors. Licensee MDPI, Basel, Switzerland. This article is an open access article distributed under the terms and conditions of the Creative Commons Attribution (CC BY) license (http://creativecommons.org/licenses/by/4.0/). 